\title{
Apuntes sobre la posición de la Alianza Bolivariana para los Pueblos de Nuestra América en la coyuntura política de Venezuela
}

Nadeska Silva Querales ${ }^{I}$

Resumen: Este artículo se plantea comprender algunos aspectos de la crisis política e institucional que confronta Venezuela en la coyuntura de los años 2018 y 2019. La crisis multidimensional ha derivado en un conflicto político entre el Poder Legislativo y el Poder Ejecutivo, lo cual impide la unicidad del Estado para revertir progresivamente la crisis económica y social en el marco de una gobernabilidad democrática que incorpore a los actores sociales. En segundo lugar, se pretende dar cuenta de la posición expresada por la Alianza Bolivariana para los Pueblos de Nuestra América - Tratado de Comercio de los Pueblos (ALBA-TCP) frente a la realidad que confronta Venezuela en el ámbito nacional e internacional.

Palabras-clave: ALBA-TCP, conflicto político, integración latinoamericana, Venezuela.

\section{Notes on the position of the Bolivarian Alliance for the Peoples of Our America about the Venezuelan political situation}

Abstract: The present article aims first to understand some aspects of the political and institutional crisis faced by Venezuela, during the 2018-2019 situation. The multidimensional crisis has led to a political conflict between the Legislative Power and the Executive Power, impeding the uniqueness of the State necessary to revert the economic and social crisis, gradually, in the framework of a democratic governance including social actors. Secondly, this document tries to present the position expressed by the Bolivarian Alliance for the Peoples of Our America - Peoples' Trade Treaty (ALBA-TCP, in its Spanish acronyms) in light of the reality faced by Venezuela, nationally and internationally.

Key words: ALBA-TCP, conflicto político, integración latinoamericana, Venezuela.

Artigo recebido em 15/10/2019 e aprovado em 27/11/2019. 


\section{APUNTES SOBRE LA POSICIÓN DE LA ALIANZA BOLIVARIANA \\ PARA LOS PUEBLOS DE NUESTRA AMÉRICA EN LA COYNTURA \\ POLÍTICA DE VENEZUELA}

NADESKA SILVA QUERALES

\section{Introducción $^{\text {II }}$}

Los procesos de integración en América Latina y el Caribe reflejan diferencias sustantivas en la construcción y funcionamiento de cada diseño político-institucional. Esto se aprecia en las prioridades económicas, el establecimiento de alianzas comerciales intra y extra regionales, el nivel de compromiso vinculante con la Agenda 2030 para el Desarrollo Sostenible, impulsada por la Comisión Económica para América Latina y el Caribe (CEPAL) en el marco de la Organización de las Naciones Unidas (ONU), así como las diversas posiciones en contra y a favor de la legitimidad legal del gobierno del presidente Nicolás Maduro Moros.

Los cursos de la integración se distinguen en la actualidad por las divergencias y la presencia de opciones integracionistas que en el plano político e ideológico contienden entre sí. En otras palabras, los procesos de integración también se constituyen de manera pública en una realidad confluida por motivaciones, intereses y tensiones entre los actores sociales regionales y extra regionales. En este sentido, se aprecian tres ejemplos palpables de dicha realidad: a) las relaciones económicas y comerciales en el seno del Mercado Común del Sur (MERCOSUR) y el Acuerdo de Asociación Estratégica suscrito en 2019 con la Unión Europea (UE) luego de transcurrir veinticuatro años de retrocesos y avances en las negociaciones ${ }^{\text {III; }}$ b) el proceso de la alianza estratégica del Foro China y la Comunidad de Estados Latinoamericanos y Caribeños (CELAC) iniciado en 2015; y c) la desintegración temporal de la Unión de Naciones Suramericana (UNASUR) mediante el retiro de Argentina, Brasil, Colombia, Chile, Perú y Paraguay en 2018 y la desincorporación de Ecuador en 2019. En la actualidad, estos países se encuentran dirigidos por gobiernos contrarios a las fuerzas políticas que encauzaron la creación de UNASUR en 2008 y su funcionamiento ulterior, además los gobiernos actuales de estos países son miembros activos del Grupo de Lima constituido en 2017 e impulsores del Foro para el Progreso del Sur (PROSUR) creado en 2019 por iniciativa de los presidentes Iván Duque (Colombia) y Sebastián Piñera (Chile).

La crisis por la cual atraviesa la sociedad venezolana es de naturaleza multidimensional y entre las causas se destaca la injerencia sistemática por parte de algunos gobiernos y estructuras en los asuntos internos, tales como los gobiernos de Estados Unidos, España, Francia, Colombia, Brasil, la Organización de Estados Americanos (OEA), la UE, el Consejo de Seguridad de la ONU y los gobiernos de los países reunidos en el Grupo de Lima ${ }^{\mathrm{IV}}$. Asimismo, en 2018 y 2019 se han efectuado reuniones e informes de organismos multilaterales, deliberaciones en foros parlamentarios, declaraciones de mecanismos de integración e instancias constituidas en Latinoamérica y fuera de la región para abordar la situación del país con miras a influir en un posible desenlace que no excluye el escenario de la violencia y la ruptura del orden constitucional. De manera simultánea se desarrollan acciones sociales por parte de organizaciones civiles y movimientos sociales que mediante narrativas ancladas en posiciones ideológicas heterogéneas expresan su respaldo o rechazo al gobierno de Maduro.

En este artículo se acomete la tarea de comprender (en el sentido weberiano) ${ }^{\mathrm{V}}$ algunos aspectos relevantes de la crisis política e institucional que confronta Venezuela en la coyuntura de los años 2018 y 2019. Esta crisis prolongada ha derivado en un 


\section{APUNTES SOBRE LA POSICIÓN DE LA ALIANZA BOLIVARIANA \\ PARA LOS PUEBLOS DE NUESTRA AMÉRICA EN LA COYNTURA POLÍTICA DE VENEZUELA}

\section{NADESKA SILVA QUERALES}

conflicto político entre el Poder Legislativo y el Poder Ejecutivo a partir de 2019, lo cual impide la unicidad del Estado para abordar la formulación y ejecución de políticas públicas que permitan revertir progresivamente la crisis económica y social en el marco de una gobernabilidad democrática que incorpore a los actores sociales en conflicto. En segundo lugar, se pretende dar cuenta de la posición pública expresada por la Alianza Bolivariana para los Pueblos de Nuestra América - Tratado de Comercio de los Pueblos (ALBA-TCP) frente a la realidad que confronta Venezuela en el ámbito nacional e internacional.

En la elaboración de este artículo se ha privilegiado la información proveniente de los actores sociales referidos con la finalidad de garantizar la veracidad de los contenidos. Es por ello que se citan las estadísticas del Banco Central de Venezuela (BCV) y el Instituto Nacional de Estadísticas (INE), luego de que estas instituciones pasarán tres años sin publicar información oficial para conocimiento de la ciudadanía. De igual manera, se emplean otras fuentes para efectuar una aproximación a la situación política, económica y social del país sin soslayar que el conflicto político también incide en los intereses de quienes generan conocimientos e información, es decir, la neutralidad valorativa es inexistente y los resultados arrojados por algunas investigaciones son utilizadas por los actores sociales intervinientes en la polarización política y dan cuenta de las motivaciones, preferencias y juicios de valor presentes en cada una de las posiciones confrontadas. Es por ello, que la comprensión de la crisis y del conflicto político en Venezuela pasa por reconocer que todo punto de vista es la vista desde un punto, lugar, actor social y posición en las relaciones de poder existentes dentro y fuera del país ${ }^{\mathrm{VI}}$.

\section{Esbozo sobre el conflicto político en Venezuela: antecedentes, tensiones y violencia}

Los gobiernos del presidente Hugo Chávez Frías (1999-2013) gozaron de altos niveles de popularidad y legitimidad legal ${ }^{\mathrm{VII}}$ a pesar de la confrontación política incesante en este periodo y de los daños causados a la incipiente cultura democrática en el país por parte de narrativas y acciones sociales (en clave weberiana) ${ }^{V I I I}$ contrarias a la voluntad popular expresada en los procesos electorales durante los catorce años de su desempeño como gobernante. Al respecto, se destacan dos hitos históricos: el golpe de Estado perpetrado por las organizaciones políticas, empresariales, sindicales y religiosas reunidas en la denominada Coordinadora Democrática con el respaldo de los principales medios de comunicación y de algunos académicos durante los días 11, 12 y 13 de abril de 2002; y el sabotaje a la industria Petróleos de Venezuela S.A. (PDVSA) en 2002 y 2003 que causó graves daños a la infraestructura, extracción, producción y comercialización de crudo en el mercado internacional ${ }^{\mathrm{IX}}$. Cabe señalar que ambos hechos mostraron la injerencia continuada por parte de los gobiernos de turno de Estados Unidos, España y Colombia.

En efecto, los gobiernos de Hugo Chávez Frías se caracterizaron por coyunturas electorales y decisiones gubernamentales que movilizaban la polarización política a tal punto que las posibilidades de diálogo entre la oposición y el gobierno nacional derivaron en experiencias circunstanciales y de escasa durabilidad. Existen muchos ejemplos de decisiones que exacerbaron las contradicciones políticas entre los gobiernos de Chávez y sectores de la oposición venezolana, a saber: 1) la convocatoria a la 


\section{APUNTES SOBRE LA POSICIÓN DE LA ALIANZA BOLIVARIANA \\ PARA LOS PUEBLOS DE NUESTRA AMÉRICA EN LA COYNTURA POLÍTICA DE VENEZUELA}

\section{NADESKA SILVA QUERALES}

Asamblea Nacional Constituyente en 1999 y la aprobación popular vía referéndum del texto constitucional; 2) las cuatro Leyes Habilitantes que le otorgaban al gobierno nacional legislar sin considerar el foro parlamentario; 3) la propuesta de Reforma Constitucional en 2007; 4) la Enmienda Constitucional en 2009; 5) las expropiaciones, la adquisición forzosa y las estatizaciones de empresas, haciendas, instituciones financieras y edificaciones; 6) las directrices de la Política Exterior de Venezuela que desde 1999 promueven la pluripolaridad, multipolaridad y las relaciones Sur-Sur ; 7) la reafirmación de la soberanía e independencia de Venezuela ante las pretensiones injerencistas de Estados Unidos; 8) las relaciones de cooperación Cuba-Venezuela y el establecimiento de relaciones económicas con China, Rusia, Irán, Libia, Palestina, la Liga Árabe y la Unión Africana; 9) la creación y financiamiento del ALBA-TCP en 2004, el impulso de la UNASUR en 2008 y el despliegue diplomático de su gobierno para apuntalar la creación de la CELAC en 2010.

No obstante, varias condiciones sustantivas influyeron a favor del chavismo durante estos catorce años de gobierno, verbigracia: los altos niveles de respaldo popular logrados en los procesos electorales y refrendarios, es decir, la legitimidad legal; las formas de organización social comunitaria impulsadas desde el Estado ${ }^{\mathrm{X}}$; el control político de la Asamblea Nacional (Poder Legislativo) por parte del Partido Socialista Unido de Venezuela (PSUV) y el Gran Polo Patriótico; los altos precios del petróleo en el mercado internacional y la renta petrolera que le proporcionaron al Estado cuantiosos recursos; las políticas sociales implementadas a través del sistema de Misiones Sociales (educativas, de salud y la red de distribución de alimentos), así como también la proyección internacional y el liderazgo carismático que permitieron al presidente Hugo Chávez Frías sortear las tensiones políticas adversas sin exponer en demasía la gobernabilidad democrática, es decir, la legitimidad, capacidad y eficacia considerable del Estado (en la perspectiva de Arbós y Giner) ${ }^{\mathrm{XI}}$ para atender las demandas de los sectores más vulnerables en el contexto de la primera década de la revolución bolivariana ${ }^{\mathrm{XII}}$

El 14 de abril de 2013 Nicolás Maduro Moros es proclamado presidente electo de Venezuela con el $50,66 \%$ de los votos mientras que el candidato de la oposición Henrique Capriles Radonski obtuvo el 49,07\% de los sufragios. Este proceso electoral se realizó tras el fallecimiento inesperado del presidente Hugo Chávez Frías, el 5 de marzo del mismo año, en cumplimiento de las disposiciones establecidas en la Constitución de la República Bolivariana de Venezuela. Como era de esperarse estos resultados no fueron reconocidos por la oposición y se inicia en el país una nueva etapa de la confrontación política que encuentra en el año 2014 el escenario para las manifestaciones y protestas en rechazo al gobierno de Maduro.

Estas protestas se expresaron a través de manifestaciones ciudadanas, concentraciones, barricadas (guarimbas), enfrentamientos entre civiles y funcionarios policiales. El gobierno de Venezuela identificó como responsables de estas acciones sociales a los dirigentes políticos Leopoldo López (Voluntad Popular), Antonio Ledezma (Alianza Bravo Pueblo) y María Corina Machado (Vente Venezuela) quienes el 23 de enero y el 12 de febrero de 2014 supuestamente incitaron a la violencia política en el país arrojando, según el Ministerio Público, el resultado de 42 fallecidos y 873 lesionados en el periodo febrero-mayo de ese año ${ }^{\text {XIII }}$. 


\section{APUNTES SOBRE LA POSICIÓN DE LA ALIANZA BOLIVARIANA \\ PARA LOS PUEBLOS DE NUESTRA AMÉRICA EN LA COYNTURA POLÍTICA DE VENEZUELA}

\section{NADESKA SILVA QUERALES}

A partir de 2014 la realidad económica y social de Venezuela ingresó en un ciclo de deterioro vertiginoso de las condiciones materiales y subjetivas de la población. Una serie de hechos simultáneos desencadenaron la profundización de la crisis estructural del modelo de desarrollo -basado principalmente en la producción, comercialización y control de la renta petrolera y minera por parte del Estado- conduciendo a la disminución de la capacidad de las instituciones públicas para atender las demandas sociales y el subsiguiente incremento de la pobreza. En 2014 se potencia el proceso de caída de los precios internacionales del petróleo y éste se agudiza en el primer semestre de 2015 cuando el crudo venezolano llega a descender a 40 dólares por barril para luego recuperarse sin lograr el precio alcanzado en los gobiernos del presidente Chávez, es decir, colocarse por arriba de los ochenta dólares o más ${ }^{\mathrm{XIV}}$.

La violencia en 2014 y la caída de los ingresos del Estado por concepto de renta petrolera estuvieron acompañadas de la primera etapa de desabastecimiento y escases de alimentos y medicinas en el país, el deterioro del salario real, el aumento de la inflación y la especulación comercial en el precio de los bienes y servicios. En ese mismo año el gobierno nacional convoca a la oposición representada por la Mesa de la Unidad Democrática (MUD) a un proceso de diálogo político facilitado por la UNASUR y el Vaticano con la finalidad de detener la violencia política y establecer un plan de trabajo para abordar la crisis económica y social en proceso de desarrollo. Sin embargo, el resultado de estas reuniones fue parcialmente satisfactorio para el gobierno nacional ya que logró detener la violencia en las calles e impedir un eventual golpe de Estado contra el presidente Nicolás Maduro ${ }^{\mathrm{XV}}$.

Las elecciones parlamentarias efectuadas el 6 de diciembre de 2015 otorgaron a la oposición política el control de la Asamblea Nacional tras una contundente victoria sobre el partido chavista PSUV y el Gran Polo Patriótico. A diferencia de la tradicional practica opositora de desconocer los triunfos electorales del chavismo, el presidente Maduro en representación del PSUV y en su condición de Jefe de Estado y de Gobierno, reconoció el triunfo de la oposición con las siguientes frases:

\footnotetext{
Ha triunfado la guerra económica, ha triunfado la estrategia para vulnerar un modelo de país. Ha triunfado circunstancialmente... Nuestro reconocimiento de los resultados estuvo garantizado. Supimos que estábamos nadando contra la corriente... ha triunfado una contrarrevolución y ha obtenido una mayoría gracias al sistema electoral impulsado en la Revolución de nuestro comandante Hugo Chávez... Liberar al país de la guerra económica, esa es la gran tarea de esta Revolución ir a lo productivo. Todo lo demás es una carta engañosa para tratar de imponer en Venezuela el modelo neoliberal ${ }^{\mathrm{XVI}}$.
}

En 2016 la llegada de la oposición política a la Asamblea Nacional desencadenó el conflicto de competencias, atribuciones y funciones entre el Poder Ejecutivo y el Poder Legislativo. El 5 de enero de 2016 el presidente de la Asamblea Nacional, diputado Henri Ramos Allup del partido Acción Democrática (AD) comunicó al país que el objetivo de la Asamblea Nacional era sacar a Nicolás Maduro de la presidencia de la República en un plazo de seis meses:

El cambio que estamos proponiendo es constitucional, pacífico y democrático, ofrecimos que en un lapso de seis meses ofreceríamos un método para cambiar el gobierno por via constitucional y lo cumpliremos ${ }^{\mathrm{XVII}}$. 


\title{
APUNTES SOBRE LA POSICIÓN DE LA ALIANZA BOLIVARIANA \\ PARA LOS PUEBLOS DE NUESTRA AMÉRICA EN LA COYNTURA \\ POLÍTICA DE VENEZUELA
}

NADESKA SILVA QUERALES

A partir de ese momento se sucede en el país un conflicto entre dos Poderes Públicos y una serie de sentencias emitidas por la Sala Constitucional del Tribunal Supremo de Justicia (TSJ) que establecen la condición de desacato de la Asamblea Nacional y, en consecuencia, la nulidad de todos los actos legislativos. Si bien cada una de las sentencias amerita de un análisis particular, el propósito expuesto en cada una establece el objetivo de resguardar supuestamente el Estado de Derecho y garantizar la gobernabilidad democrática.

En 2017 es convocada una Asamblea Nacional Constituyente (ANC) por el presidente Maduro en Consejo de Ministros ${ }^{\mathrm{XVIII}}$, luego de los hechos de violencia ocurridos durante el primer semestre de ese año, con la intención de redactar una nueva constitución y contener la ola de protestas, movilizaciones y barricadas (guarimbas) que apuntaban de nuevo hacia un golpe de Estado o provocar la renuncia del presidente Maduro. Los 500 miembros de la ANC fueron electos el 30 de julio de 2017 y en la actualidad permanecen en funciones. Según el abogado constitucionalista Hermann Escarrá, el propósito de la ANC es el siguiente:

\begin{abstract}
Básicamente es adicionar los programas sociales, las conquistas sociales, la reorganización del Estado, entre otros aspectos... Lo que está planteado es un diálogo superior en medio del gravísimo conflicto y violencia en la que comienza a desenvolverse la situación de Venezuela... la única vía que queda para que no se produzca en Venezuela un hecho grave es convocar a una Asamblea Constituyente ${ }^{\mathrm{XIX}}$.
\end{abstract}

Los debates políticos entorno a la legitimidad legal de la convocatoria de una ANC en 2017 fueron prolijos y ameritan de un análisis sociológico más riguroso. La oposición política representada en la Asamblea Nacional y los partidos integrantes de la MUD desconocen la legitimidad legal y las funciones de la ANC, en general consideran que la misma es una estrategia del gobierno nacional para neutralizar la capacidad legislativa representada por el parlamento electo en 2015 y frenar las protestas en las principales ciudades del país. En un comunicado oficial la MUD señaló:

\footnotetext{
La Mesa de la Unidad Democrática, acompañada de los diputados electos el 6 de diciembre de 2015 y de todos los venezolanos y venezolanas que nos acompañan en esta lucha, le entregamos nuestra respuesta, en la cual rechazamos participar en la fraudulenta e ilegítima propuesta de Nicolás Maduro... solo el pueblo puede decidir, mediante referendo, si quiere o no convocar a una constituyente y ningún poder del Estado puede usurpar las funciones que le corresponden al pueblo. Los poderes que tienen la iniciativa de convocatoria, deberán obligatoriamente consultar al ciudadano a través de referendo. $\mathrm{XX}$
}

En los años 2018 y 2019 se ha agudizado el conflicto entre los Poderes Ejecutivo y Legislativo, así como la crisis económica y social. Al respecto, cabe destacar que en 2017 la presidencia de la Asamblea Nacional ejercida por el diputado Julio Borges del Partido Primero Justicia, se abocó a exponer en el ámbito internacional la situación de Venezuela y el antagonismo existente entre los polos en conflicto por el control del Estado y sus riquezas (petróleo, gas, minería y biodiversidad). Estas acciones sociales 


\section{APUNTES SOBRE LA POSICIÓN DE LA ALIANZA BOLIVARIANA \\ PARA LOS PUEBLOS DE NUESTRA AMÉRICA EN LA COYNTURA POLÍTICA DE VENEZUELA}

\section{NADESKA SILVA QUERALES}

facilitaron que el debate sobre la realidad venezolana ocupara de manera relevante a la Secretaría General de la OEA, el parlamento de la UE, las instituciones del MERCOSUR, el Consejo de Seguridad de la ONU, entre otras acciones sociales que simultáneamente se articulan en una alianza política de la coalición opositora con los gobiernos de Jair Bolsonaro (Brasil), Sebastián Piñera (Chile), Mauricio Macri (Argentina) $^{\mathrm{XXI}}$, Iván Duque (Colombia) y Lenin Moreno (Ecuador) bajo el mando y la coordinación del gobierno de Donald Trump en Estados Unidos.

El propósito de esta alianza política internacional tejida y consolidada por la oposición a partir de 2017 es lograr la salida del poder de Nicolás Maduro mediante una estrategia que incluye una gama de acciones sociales combinadas (persuasión, disuasión y violencia), las cuales pueden sintetizarse de la siguiente manera: 1) la implementación de sanciones económicas y financieras contra el Estado y personalidades del alto gobierno principalmente impuestas por Estados Unidos y la UE; 2) bloqueos de activos y cuentas de PDVSA en otros países; 3) denuncias continuas sobre la violación de los derechos humanos en Venezuela ante la Oficina del Alto Comisionado para los Derechos Humanos de la ONU ${ }^{\mathrm{XXI}}$, la Comisión Interamericana de Derechos Humanos de la OEA ${ }^{\text {XXIII }}$ y la Fiscalía de la Corte Penal Internacional ${ }^{\text {XXIV }}$; 4) creación del Grupo de Lima para impulsar el cerco regional contra el gobierno de Maduro ${ }^{\mathrm{XX}}$; 5) intento frustrado de magnicidio el 4 de agosto de $2018^{\mathrm{XXVI}}$; 6) protestas y movilizaciones focalizadas en algunas localidades del país para solicitar la renuncia del presidente Maduro y alentar la intervención militar extranjera; 7) protestas frente a embajadas y consulados de Venezuela para respaldar las acciones sociales opositoras en el ámbito internacional; 8) desconocimiento de la legitimidad legal del gobierno de Nicolás Maduro mediante la autoproclamación del diputado Juan Guaidó como presidente "encargado" de la República; 9) crisis en el sistema eléctrico nacional potenciada por el sabotaje de este servicio; 10) ataque a la moneda nacional (bolívar soberano) mediante los marcadores paralelos que establecen el valor del dólar y el euro fuera del país ${ }^{\mathrm{XVII}}$; 11) programación de desabastecimiento de alimentos y medicinas para fundamentar la existencia de una crisis humanitaria generalizada y justificar la aplicación de las acciones sociales planteadas ante la ONU en el año 2001 por la Comisión Internacional sobre Intervención y Soberanía de los Estados (CIISE) bajo la denominación "Responsabilidad de Proteger"XXVIII; y 12) intentos frustrados de golpe de Estado en 2019. Si bien todas estas acciones sobrepasan los límites trazados por este artículo es imprescindible dar cuenta, grosso modo, de la multiplicidad de hechos que han estado presentes en la coyuntura sociopolítica venezolana.

Ciertamente, el país atraviesa por una crisis económica y social de gran complejidad que amerita de un proceso de negociación que derive en un acuerdo nacional -en el marco de la Constitución y las leyes de la república- entre los actores sociales para reactivar el aparato productivo y retomar la senda del crecimiento económico junto con políticas de inclusión social de carácter universal (el compromiso con la Agenda 2030 para el Desarrollo Sostenible), recuperar la producción de la industria petrolera (PDVSA), corregir los desequilibrios macroeconómicos y en particular revertir el proceso hiperinflacionario -iniciado en noviembre de 2017- que ha desmejorado el valor social del trabajo, socavado el salario real, incrementado la pobreza y la diáspora venezolana, entre otras decisiones impostergables para mejorar las condiciones de vida de la ciudadanía y fortalecer la gobernabilidad democrática. 


\section{APUNTES SOBRE LA POSICIÓN DE LA ALIANZA BOLIVARIANA \\ PARA LOS PUEBLOS DE NUESTRA AMÉRICA EN LA COYNTURA POLÍTICA DE VENEZUELA}

\section{NADESKA SILVA QUERALES}

En este orden de ideas, las estadísticas publicadas por el Banco Central de Venezuela $(\mathrm{BCV})$ revelan la complejidad de la prolongada recesión económica del país, la cual inicia en el primer trimestre de 2013 cuando el Producto Interno Bruto (PIB) se ubicó en $-5,2 \%$ hasta situarse en el primer trimestre de 2019 en $-26,8 \%{ }^{\text {XXIX }}$. Según la misma fuente oficial la inflación acumulada en Venezuela muestra un incremento alarmante en los últimos cinco años: 27,6\% (2011), 20,1\% (2012), 56,2 \% (2013), $68,5 \%$ (2014) $180,9 \%$ (2015), $274 \%$ (2016), $862,6 \%(2017)$ y $130.060 \%(2018)^{\mathrm{XXX}}$.

El BCV informó que el Índice de Precios al Consumidor en el mes de septiembre de 2019 se ubicó en 5.286.006.314,7 puntos, la inflación del mes en 52,2\% mientras que la acumulada en el año es $4.679,50 \%$ y la anualizada en $39.113,75 \%$ XXXI . Por su parte, la Asamblea Nacional, presidida por el diputado Juan Guaidó, presentó el 9 de octubre de 2019 una estimación de la inflación para el mes de septiembre inferior a los datos del BCV. Según la Asamblea Nacional la inflación de septiembre fue de 23,5\% mientras que la variación acumulada durante el año se ubicó en $3.326 \%$ y la inflación interanual en $50.100,3 \%$ XXXII.

Otro indicador relevante por su impacto directo en el funcionamiento de la economía tiene que ver con las reservas internacionales y la deuda externa contraída por el Estado. Al cierre del primer semestre de 2013 las reservas internacionales se situaron en 25.804 millones de dólares mientras que en el primer semestre de 2019 en 8.113 millones de dólares ${ }^{X X X I I I}$. El BCV también informa sobre la evolución de la deuda externa en Venezuela, por ejemplo en el primer trimestre de 1999 la deuda externa era de 35.403 millones de dólares, más adelante en el primer trimestre de 2013 la deuda externa se ubicó en 130.362 millones de dólares mientras que en el primer trimestre de 2019 es de 110.159 millones de dólares ${ }^{\text {XXIV }}$.

En síntesis, la reducción de las reservas internacionales, el descenso de la producción de petróleo ${ }^{\mathrm{XXV}}$, los compromisos financieros (deuda externa) del Estado con otros países y la hiperinflación complejizan el panorama económico nacional. La crisis económica tiene sus repercusiones inmediatas en el aumento de la pobreza, la precarización del trabajo y en el incremento del flujo migratorio de venezolanos a lo interno de América Latina y fuera de la región.

Existe una variedad de fuentes informativas con respecto a las metodologías y datos sobre el comportamiento de la pobreza en el país, por ejemplo la Encuesta Nacional de Condiciones de Vida (ENCOVI) realizada por la Universidad Católica Andrés Bello, la Universidad Central de Venezuela y la Universidad Simón Bolívar XXXVI, así como también las mediciones efectuadas por el Centro de Documentación y Análisis para los Trabajadores (CENDA) ${ }^{\text {XXVII }}$. El Instituto Nacional de Estadística (INE) divulgó en 2018 las estadísticas oficiales con respecto a la pobreza en Venezuela y según sus mediciones la pobreza en el país se expresa en los siguientes datos:

La pobreza se mide por distintos métodos. La pobreza estructural está asociada las necesidades básicas insatisfechas contemplando variables como escolaridad, dependencia escolar, servicios, hacinamiento crítico y viviendas inadecuadas.

$\checkmark \quad$ El porcentaje de hogares en pobreza extrema estructural, medida por Necesidades Básicas Insatisfechas (NBI), disminuyó a 4,3\% en el año 2018, 


\title{
APUNTES SOBRE LA POSICIÓN DE LA ALIANZA BOLIVARIANA \\ PARA LOS PUEBLOS DE NUESTRA AMÉRICA EN LA COYNTURA POLÍTICA DE VENEZUELA
}

\section{NADESKA SILVA QUERALES}

\author{
mientras que en el año 1998 era de 10,8\%. Por su parte la pobreza general ha \\ pasado de $29 \%$ a $17 \%$. \\ $\checkmark \quad$ Hogares Pobres. Año 1999: 1.453.606. Año 2018: 1.419.595. \\ Esto significa que 34.011 hogares salieron de la pobreza. \\ $\checkmark \quad$ Hogares Pobres Extremos. Año 1999: 493.264. Año 2018: 351.379. \\ Esto significa que 141.885 hogares dejaron de ser pobres extremos. \\ $\checkmark \quad$ El Coeficiente de Gini muestra mejoras en la distribución de la \\ riqueza. Este indicador mejoró significativamente, al pasar de 0,469 en 1999 \\ a 0,377 en 2018. Venezuela tiene un compartimiento en la región en el \\ coeficiente Gini, y la política estructural a la reducción de desigualdades, \\ como consecuencia del modelo social de protección al pueblo.
}

La realidad económica y social antes descrita se complejiza mucho más con el desconocimiento público e internacional, por parte de la oposición, de Nicolás Maduro Moros como presidente constitucional de Venezuela para el periodo 2019-2025. La oposición representada en la Asamblea Nacional, la MUD y el Frente Amplio Venezuela Libre desconoce los resultados de las elecciones presidenciales realizadas el 20 de mayo de 2019 por su condición ilegítima y fraudulenta. Según el Consejo Nacional Electoral (CNE) Nicolás Maduro es reelecto con 5.823.728 votos (67.7\%) y con una participación electoral de $48 \%$ mientras que el segundo candidato más votado fue Henri Falcón, del partido Avanzada Progresista (AP) con 1 millón 820.552 votos (21.1\%) de los sufragios XXXVIII.

El 10 de enero de 2019 Nicolás Maduro es juramentado presidente de la República por el TSJ para asumir un segundo mandato. El TSJ realizó la juramentación en vista del desacato en el cual se encuentra la Asamblea Nacional desde el 11 de enero de 2016 por decisión del TSJ. El diputado Juan Guaidó (Voluntad Popular) es juramentado presidente de la Asamblea Nacional el 5 de enero de 2019 y en respuesta a la juramentación del presidente Maduro decide con el apoyo de la coalición opositora y el respaldo internacional de varios gobiernos, proclamarse presidente de Venezuela el 23 de enero del mismo año. En palabras del diputado Juan Guaidó:

\footnotetext{
Juro asumir formalmente las competencias del Ejecutivo nacional como el presidente encargado de Venezuela para lograr el cese de la usurpación, un gobierno de transición y tener elecciones libres ${ }^{\mathrm{XXIX}}$
}

A partir de este hecho se generó un conflicto político entre los Poderes Ejecutivo y Legislativo, se reactivó la polarización interna con grandes repercusiones internacionales. En efecto, la juramentación del diputado Juan Guaidó fue seguida de pronunciamientos a su favor por parte de los gobiernos de Estados Unidos, Israel, Francia, España, Alemania, Canadá, Portugal, Inglaterra, Colombia, Perú, Paraguay, Argentina, Brasil, Ecuador, Chile, Costa Rica, Honduras, Panamá y Bahamas, entre otros. La Secretaría General de la OEA, el parlamento europeo y varios países de la UE se sumaron a las acciones sociales de la oposición en apoyo al diputado Guaidó y siguiendo la ruta trazada por el gobierno estadounidense de Donald Trump.

El 30 de abril de 2019 la oposición política liderada por el partido Voluntad Popular, bajo la conducción del diputado Juan Guaidó y Leopoldo López, intentó nuevamente un Golpe de Estado contra el presidente Nicolás Maduro. Esta acción 


\section{APUNTES SOBRE LA POSICIÓN DE LA ALIANZA BOLIVARIANA \\ PARA LOS PUEBLOS DE NUESTRA AMÉRICA EN LA COYNTURA POLÍTICA DE VENEZUELA}

\section{NADESKA SILVA QUERALES}

social fue dirigida desde los gobiernos de Estados Unidos y Colombia pero no alcanzó la receptividad, respaldo y movilización popular esperada por la oposición.

La proclamación de Juan Guiadó como "presidente encargado de Venezuela para lograr el cese de la usurpación" y las acciones sociales posteriores (incremento de las sanciones económicas y financieras impuestas por de Estados Unidos e intento de golpe de Estado) no han logrado el objetivo de provocar una ola de protestas sociales que conduzcan a la renuncia, destitución o salida por la fuerza del presidente Maduro.

Por último, el gobierno nacional ha promovido en 2019 varios procesos de diálogo con la oposición para avanzar en la resolución del conflicto político y fortalecer la gobernabilidad democrática en el país. De igual manera, el gobierno del presidente Maduro ha contado con el respaldo de un significativo número de países, mecanismos de integración y organismos internacionales, a saber: Rusia, China, Turquía, Irán, Siria, Palestina, Uruguay, México, la Unión Africana, el ALBA-TCP, la Comunidad del Caribe (CARICOM), la CELAC, la Secretaría General de la ONU, el Movimiento de los No Alineados (MNOAL) y la OPEP. Este respaldo al gobierno del presidente Maduro evidencia, en cierta medida, que el aislamiento o cerco internacional que pretendía imponer la coalición opositora y sus aliados foráneos, así como la estrategia de internacionalización del conflicto venezolano no ha logrado su propósito en el trienio 2017-2019 a pesar de la compleja crisis económica y social que atraviesa el país.

En el siguiente apartado se recogen las principales declaraciones del ALBA-TCP con respecto al conflicto político en Venezuela durante los años 2018 y 2019.

\section{La Alianza Bolivariana para los Pueblos de Nuestra América - Tratado de Comercio de los Pueblos: principios fundacionales, perspectiva internacional $\mathbf{y}$ posición sobre Venezuela}

La Alianza Bolivariana para los Pueblos de Nuestra América - Tratado de Comercio de los Pueblos (ALBA-TCP) es un mecanismo de integración que se constituye el 14 de diciembre de 2004 por decisión de los presidentes de Venezuela y Cuba, Hugo Chávez Frías y Fidel Castro respectivamente. Desde 2004 hasta el presente busca promover el multilateralismo, la pluripolaridad, la cooperación e integración a partir de los principios fundacionales que le dieron origen (solidaridad, autodeterminación de los pueblos, la complementariedad y ayuda mutua) en contraposición a los enfoques de integración económica y comercial planteados por el Área de Libre Comercio de las Américas (ALCA) y los Tratados de Libre Comercio (TLC) impulsados en América Latina por Estados Unidos, Canadá, Japón, Israel, la UE y la Alianza del Pacífico ${ }^{\mathrm{XL}}$. La ALBA-TCP siendo una experiencia subregional se articula con la UNASUR y la CELAC por existir ciertas visiones compartidas en el ámbito de las relaciones internacionales.

La experiencia del ALBA-TCP es de quince años y en este trayecto ha pasado por varias etapas en su desarrollo político-institucional, las cuales se resumen a continuación: 1) la fundacional que inaugura la alianza política entre los gobiernos de Cuba y Venezuela; 2) las primeras adhesiones que dan inicio a la construcción de una alianza de mayor espectro en la subregión con la inclusión de Bolivia, Nicaragua y Ecuador; 3) la definición de un ambicioso plan de trabajo (suscripción del Proyecto Grannacional en 2007) que propone una pléyade de áreas, acuerdos y proyectos para la 


\section{APUNTES SOBRE LA POSICIÓN DE LA ALIANZA BOLIVARIANA \\ PARA LOS PUEBLOS DE NUESTRA AMÉRICA EN LA COYNTURA POLÍTICA DE VENEZUELA}

\section{NADESKA SILVA QUERALES}

integración y la democratización del acceso al petróleo (creación de PetroCaribe); 4) el reconocimiento y proyección de resultados, logros y perspectivas de alcance regional con capacidad política e influencia en foros de carácter multilateral, por ejemplo en la OEA, CELAC y el MNOAL; y 5) a partir de 2014 una etapa de ralentización y opacidad en la información que coincide con tres hechos importantes: el fallecimiento del presidente Hugo Chávez Frías en 2013, la baja de los precios del crudo en el mercado internacional y la crisis económica, social y política en Venezuela ${ }^{\mathrm{XLI}}$.

En la actualidad los países que integran el ALBA-TCP son los siguientes: Venezuela, Cuba, Bolivia, Nicaragua, Mancomunidad de Dominica, Antigua y Barbuda, San Vicente Las Granadinas y Santa Lucía. Cabe destacar que Honduras se retira en 2010 debido al golpe de Estado contra Manuel Zelaya y el 23 de agosto de 2018 el gobierno del presidente Lenin Moreno informó el retiro de Ecuador del mecanismo por sus diferencias con el gobierno del presidente Maduro y en respaldo a la oposición política venezolana. Al respecto, es necesario recapitular que el gobierno de Lenin Moreno fracciona -a las pocas semanas de asumir el poder- su alianza política con el ex presidente ecuatoriano Rafael Correa (2007-2017), retira a su país del ALBA-TCP y UNASUR, respalda las acciones internacionales del Grupo de Lima, se apunta a la creación de ProSur, retoma la perspectiva económica neoliberal en Ecuador bajo la égida del Fondo Monetario Internacional y desde 2018 está en proceso de negociación de un TLC con Estados Unidos ${ }^{\text {XLII }}$.

En la actualidad las informaciones sobre el quehacer institucional del ALBA-TCP son escasas dado que el sitio oficial (http://alba-tcp.org/) se encuentra fuera de línea desde hace dos años aproximadamente. Es por ello que se emplean las fuentes oficiales de Cuba y Venezuela, así como los medios de comunicación digitales que reseñan su funcionamiento e intervenciones con respecto a Venezuela.

En el año 2018 realizaron dos cumbres del ALBA-TCP. La XV Cumbre de Jefes de Estados y de Gobierno se llevó a cabo el 5 de marzo en Caracas y fue suscrita una Declaración mediante la cual retoma la vigencia de algunos compromisos fundacionales que son objeto del quehacer diplomático a lo interno y fuera de la alianza en pro de la integración latinoamericana y caribeña:

\footnotetext{
...continuar impulsando la construcción de un nuevo orden internacional, justo e inclusivo, multicéntrico y pluripolar, en contraposición a las tendencias hegemónicas y unilaterales, con estricto respeto a los pueblos, a las Instituciones elegidas por ellos y a las diversas culturas que existen en nuestro planeta.

... Reiteramos nuestro compromiso con la unidad latinoamericana y caribeña, en la búsqueda de un destino propio, independiente y soberano, sin tutelaje ni injerencias que afecten a nuestros pueblos y su desarrollo,reivindicamos nuestro pleno compromiso con los procesos de integración genuinamente latinoamericanos y caribeños como CELAC, UNASUR, PETROCARIBE, CARICOM y el ALBA-TCP, para garantizar la soberanía, independencia, igualdad y autodeterminación de nuestros pueblos ${ }^{\text {XLIII }}$.
}

En este documento también expresa el rechazo a la aplicación de la Doctrina Monroe, denuncian las amenazas y agresiones contra el gobierno de Venezuela y, de manera particular, cuestionan las acciones injerencistas del Secretario General de la OEA, Luis Almagro, y del Grupo de Lima contra el Estado venezolano. 


\title{
APUNTES SOBRE LA POSICIÓN DE LA ALIANZA BOLIVARIANA \\ PARA LOS PUEBLOS DE NUESTRA AMÉRICA EN LA COYNTURA POLÍTICA DE VENEZUELA
}

\section{NADESKA SILVA QUERALES}

\begin{abstract}
Expresamos nuestro desacuerdo con el pronunciamiento de un grupo de países del continente, emitido el 13 de febrero de 2018 en Lima, Perú, que constituye una intromisión en los asuntos internos de la República Bolivariana de Venezuela. Rechazamos la exclusión de la hermana República Bolivariana de Venezuela y de su Presidente, Nicolás Maduro Moros, de la VIII Cumbre de las Américas, pues consideramos que dicha Cumbre debe ser un punto de encuentro para todos los Estados del continente y un espacio donde todos podamos expresar nuestras ideas, alcanzar consensos, disentir y debatir respetando nuestra diversidad.

... Exhortamos a la comunidad internacional a abstenerse de ejercer coerción de cualquier tipo, en contra de la independencia política y la integridad territorial de Venezuela, como práctica incompatible con los principios del Derecho Internacional y de la Carta de las Naciones Unidas, y contraria a la Proclama de América Latina y el Caribe como Zona de Paz ${ }^{\text {XIV }}$.
\end{abstract}

En esta cumbre no fueron referidos logros del ALBA-TCP ni tampoco mencionaron los acuerdos y proyectos en marcha, sin embargo, quedó asentado el compromiso de fortalecer la CELAC y la UNASUR mediante el apoyo a la presidencia Pro Témpore de Bolivia.

Los días 14 y 15 de diciembre de 2018 se reunieron en La Habana para realizar la XVI Cumbre de Jefes de Estados y de Gobierno bajo el título "En defensa de América Latina y el Caribe como Zona de Paz". En este encuentro ratificaron el apoyo de esta alianza a los gobiernos de Nicolás Maduro (Venezuela), Evo Morales (Bolivia), Raúl Castro (Cuba) y Daniel Ortega (Nicaragua), consecutivamente amenazados por la política exterior de Estados Unidos en América Latina.

La Declaración emanada de la XVI Cumbre del ALBA-TCP consta de veinticinco puntos, revalida en el discurso su compromiso con la integración latinoamericana y caribeña como expresión de soberanía, autodeterminación, justicia e inclusión social alineada con el multilateralismo, la cooperación Sur-Sur y la opción por un orden internacional multicéntrico y pluripolar. Al igual que en la XV Cumbre expresa rechazo contra la injerencia de Estados Unidos en Venezuela, la imposición de sanciones unilaterales, la pretensión de un cerco internacional contra el país y, además, reconoce en los numerales 9, 10 y 11 la legitimidad legal del presidente Maduro, resultante de las elecciones presidenciales celebradas el 20 de mayo de 2018:

\footnotetext{
Destacamos la resistencia del Gobierno y pueblo venezolanos frente a la injerencia externa, las medidas coercitivas unilaterales y la constante manipulación mediática contra su país.

Reiteramos nuestro apoyo y reconocimiento al gobierno electo del presidente Nicolás Maduro Moros a quien auguramos éxitos en su gestión al frente de la República Bolivariana de Venezuela, a partir de la toma de posesión del próximo 10 de enero de 2019.

Rechazamos el accionar injerencista del Gobierno de Estados Unidos, que utiliza una vez más a la OEA en su política intervencionista contra la soberanía, la libre determinación y el orden constitucional de la República Bolivariana de Venezuela, de la República de Nicaragua y de otros países. ${ }^{\text {XLV }}$
}

Este esquema de integración también reprobó el intento de magnicidio perpetrado contra el presidente venezolano en la avenida Bolívar de la ciudad de Caracas, ocurrido el 4 de agosto de 2018: 


\title{
APUNTES SOBRE LA POSICIÓN DE LA ALIANZA BOLIVARIANA \\ PARA LOS PUEBLOS DE NUESTRA AMÉRICA EN LA COYNTURA POLÍTICA DE VENEZUELA
}

\author{
NADESKA SILVA QUERALES
}

Para los países del ALBA-TCP todos los actos, métodos y prácticas terroristas, en todas sus formas y manifestaciones, son hechos repudiables que atentan contra la vida y la paz de nuestros pueblos. En este sentido, la Secretaria Ejecutiva del ALBA-TCP expresa su más firme condena y rechazo a este atentado terrorista ocurrido en Caracas en contra del Hermano Presidente Nicolás Maduro. Igualmente, expresamos nuestra solidaridad y deseos de pronta recuperación a los ciudadanos venezolanos que resultaron heridos durante este atentado ${ }^{\mathrm{XLVI}}$.

Las declaraciones del ALBA-TCP en el año 2019 están orientadas principalmente a reafirmar la soberanía de los Estados y la gobernabilidad democrática a lo interno del bloque. En este sentido, se destaca en un comunicado de fecha 24 de enero de 2019 el rechazo a las acciones sociales de la oposición venezolana que buscan desconocer la legitimidad legal del gobierno de Maduro y colocar al diputado Juan Guaidó en calidad de presidente "encargado" de Venezuela:

Nuestros países sólo reconocen como representantes de Venezuela en los ámbitos multilateral y bilateral a los funcionarios diplomáticos designados por el Poder Ejecutivo de Venezuela, el cual encabeza su presidente Nicolás Maduro XLVII

El 30 de abril de 2019 en otra acción social al margen de la Constitución y las leyes de Venezuela, la oposición liderada por el partido Voluntad Popular, del cual forman parte el diputado Juan Guaidó y Leopoldo López, intentaron un golpe de Estado contra el gobierno del presidente Maduro. Al respecto, en otro comunicado oficial el ALBA-TCP señaló:

Para el ALBA-TCP los hechos que se desarrollan desde tempranas horas del martes 30 de abril de 2019 en Caracas son claramente un intento de golpe de Estado auspiciado y propiciado por fuerzas políticas radicales de la derecha venezolana en complicidad con los enemigos históricos de la independencia y soberanía de nuestros pueblos de América Latina y el Caribe. El ALBA-TCP denuncia ante la comunidad internacional este nuevo intento de golpe de Estado en contra del gobierno bolivariano de Venezuela. Igualmente, exige el respeto pleno al orden constitucional y al Estado de Derecho de la República Bolivariana de Venezuela y alerta sobre las consecuencias que para Nuestra América tendría la ruptura del orden constitucional en Venezuela ${ }^{\mathrm{XLVIII}}$

En el marco del XVIII Consejo Político del ALBA-TCP efectuado en La Habana el 21 de mayo de 2019 este mecanismo volvió a reiterar su solicitud de respeto a la soberanía de Venezuela y la eliminación de las sanciones impuestas por Estados Unidos y algunos países de la UE contra el gobierno del presidente Maduro. En esta Declaración también respaldan el proceso de diálogo entre la oposición y representantes del gobierno nacional:

Llamamos a respaldar la iniciativa del "Mecanismo de Montevideo", integrada por México, Uruguay, Bolivia y CARICOM, que busca preservar la paz en Venezuela basada, en los principios de no intervención en los asuntos internos, la igualdad soberana de los Estados y la solución pacífica de controversias. 


\title{
APUNTES SOBRE LA POSICIÓN DE LA ALIANZA BOLIVARIANA \\ PARA LOS PUEBLOS DE NUESTRA AMÉRICA EN LA COYNTURA POLÍTICA DE VENEZUELA
}

\author{
NADESKA SILVA QUERALES
}

\begin{abstract}
Demandamos la estricta observancia de los Propósitos y Principios de la Carta de las Naciones Unidas y el Derecho Internacional, la solución pacífica de controversias, la prohibición del uso de la fuerza y de la amenaza del uso de la fuerza, el respeto a la libre determinación, a la soberanía, la integridad territorial, y la no injerencia en los asuntos internos de los Estados ${ }^{\text {XLIX }}$.
\end{abstract}

El 23 de septiembre de 2019 en la Declaración del XIX Consejo Político del ALBA-TCP realizada en el contexto del 74 Período de Sesiones de la Asamblea General de la ONU, rechazaron la pretensión de activar el Tratado Interamericano de Asistencia Recíproca (TIAR) contra Venezuela, así como el hostigamiento y las amenazas contra la paz e integridad territorial de este país. En este sentido, señalaron que las pretendidas acciones sociales de la OEA contra Venezuela son ilegales y violatorias del Derecho Internacional:

.. la Resolución CP/RES. 1137 (2245/19) de la Organización de Estados Americanos (OEA) aprobada el pasado 11 de septiembre de 2019, es absolutamente ilegal y violatoria del Derecho Internacional de forma y fondo debido a que la República Bolivariana de Venezuela no es parte de la OEA desde abril de 2019 y tampoco del Tratado Interamericano de Asistencia Recíproca ya que denunció dicho Acuerdo en mayo de $2013^{\mathrm{L}}$.

La posición del ALBA-TCP con respecto a la situación interna de Venezuela y el conflicto político entre los Poderes Ejecutivo y Legislativo se circunscribe en los criterios fundacionales que sirvieron de base para la estructuración de la alianza entre los países que la integran. Esto es, la voluntad política de reconfigurar el orden internacional mediante el multilateralismo, el respeto al Derecho Internacional y la soberanía de cada Estado sobre su territorio en atención a las directrices que sustentan el Estado de Derecho en cada país. De igual manera, el apuntalamiento de las ideasfuerzas del multilateralismo, la pluripolaridad, la multicentralidad y la cooperación SurSur en una estrategia defensiva y ofensiva que devela, denuncia y rechaza la política exterior de Estados Unidos hacia América Latina.

\section{A modo de cierre abierto}

La crisis multidimensional que transita Venezuela a partir de 2014 lejos de encontrar su resolución, se agravó luego de los hechos ocurridos en el trienio 20172019. Las opciones para la recuperación del crecimiento económico, la diversificación productiva y la reversión de la pobreza requieren de un proceso de diálogo y negociación entre los actores sociales que dinamizan el conflicto político y el gobierno de Nicolás Maduro. La injerencia ininterrumpida del gobierno de Donald Trump y de los países agrupados en el Grupo de Lima, en su condición de aliados de la coalición opositora en Venezuela, complejiza aún más las alternativas para la resolución del conflicto entre el Poder Ejecutivo y el Poder Legislativo.

De igual manera, puede observarse que el tablero internacional con respecto a los apoyos o rechazo a las acciones sociales de la oposición es heterogéneo y de alcance significativo. En el caso del gobierno nacional se aprecia que esta diversidad incluye tanto gobiernos de otros países como estructuras internacionales de relevancia por el 


\section{APUNTES SOBRE LA POSICIÓN DE LA ALIANZA BOLIVARIANA \\ PARA LOS PUEBLOS DE NUESTRA AMÉRICA EN LA COYNTURA POLÍTICA DE VENEZUELA}

\section{NADESKA SILVA QUERALES}

número de miembros que agrupan, por ejemplo la ONU, Unión Africana, CARICOM, OPEP y ALBA-TCP.

En cuanto al ALBA-TCP se aprecia que este mecanismo ha mantenido su cohesión política interna y la unicidad ante el conflicto político en Venezuela. Los principios fundacionales que dieron asidero a este mecanismo en 2004 figuran el constructo para el análisis sobre la realidad internacional y la estabilidad de su respuesta ante las acciones sociales de la diplomacia estadounidense en América Latina y el Caribe. El ALBA-TCP aboga por el diálogo y la resolución pacífica del conflicto político en Venezuela, así como también por el respeto de la soberanía, la autodeterminación y la política exterior del país.

\section{Notas}

I Socióloga egresada de la Universidad Central de Venezuela (1994). Magíster en Ciencia Política por la Universidad Simón Bolívar (1999). Profesora de la Cátedra de Sociología en la Escuela de Estudios Políticos y Administrativos de la Universidad Central de Venezuela en los años 20062009 y en la Cátedra de Teoría Política de la Escuela de Sociología de la misma universidad en los años 2000-2004. Desde el año 2006 Investigadora-Docente del Instituto de Altos Estudios Diplomáticos Pedro Gual (IAEDPG). Temas de especialización: teoría social y política, dimensión política y social de los mecanismos de integración regional y subregional en América Latina, procesos y políticas públicas de inclusión social, ciudadanía, democracia y participación sociopolítica.

${ }^{\text {II }}$ Este artículo se realiza en el marco de un proyecto de investigación que comprende el desenvolvimiento y las transformaciones de la dimensión política y social del MERCOSUR, ALBA, UNASUR y CELAC, las tensiones intereses, conflictos y alianzas entre los actores sociales en el siglo XXI. En este artículo agradecemos especialmente el apoyo de Marcia Peña (licenciada en Historia e investigadora del IAEDPG), Gabriel Duque Hidalgo (economista), Virginia Campos (licenciada en idiomas y Magíster en Relaciones Internacionales) y a Inocencio Pereira, coordinador del Centro de Información, Documentación Especializado en Relaciones Exteriores (CIDERE) del IAEDPG.

III En 1995 iniciaron las negociaciones entre el MERCOSUR y la UE, posteriormente la primera ronda de negociaciones se desarrolló en el año 2000, la reactivación de las negociaciones en 2016 y el 28 de junio de 2019 suscriben en Bruselas el Acuerdo de Asociación Estratégica con la UE.

IV El Grupo de Lima se constituye en la ciudad de Lima el 8 de agosto de 2017 y la Declaración es firmada por los Cancilleres y Representantes de Argentina, Brasil, Canadá, Chile, Colombia, Costa Rica, Guatemala, Honduras, México, Panamá, Paraguay y Perú.

V Siguiendo a Weber (2006a, 175-176) se asume por comprensión: "Al igual que todo acaecer, la conducta humana ("externa" o "interna") muestra nexos o regularidades. Sin embargo, hay algo que es propio solamente de la conducta humana, al menos en sentido pleno: el curso de regularidades y nexos es interpretable por vía de comprensión. Una "comprensión" de la conducta humana por medio de interpretación contiene ante todo una "evidencia" cualitativa específica, de dimensión singularísima. El que una interpretación posea esta evidencia en medida muy alta nada prueba en sí en cuanto a su validez empírica. En efecto, un comportamiento igual en su curso y su resultado externo puede descansar en constelaciones o motivos de índole muy diversa, entre los cuales los comprensibles de manera más evidente no siempre han sido los realmente en juego. Antes bien, el "comprender" determinado nexo ha de ser controlado, en la medida de lo posible, con los métodos usuales de la imputación causal antes de que una interpretación, no importa cuán evidente, pase a ser una "explicación comprensible" válida. Ahora bien, la interpretación racional con arreglo a fines (zweckrationales) es la que posee el grado máximo de evidencia".

${ }^{\mathrm{VI}}$ Este aspecto es muy importante a los efectos de comprender el por qué existen discursos encontrados y producciones académicas que responden a la dinámica y funcionalidad de la polarización política entorno a la crisis en Venezuela. Esta confrontación potencia la fuerza social que retroalimenta el conflicto sin aparente resolución a mediano plazo. Es por ello que en este trabajo rescatamos la aportación de Max Weber $(2006$ b, 44) sobre la ciencia y los juicios de valor: "Una ciencia empírica no puede enseñar a nadie 


\title{
APUNTES SOBRE LA POSICIÓN DE LA ALIANZA BOLIVARIANA \\ PARA LOS PUEBLOS DE NUESTRA AMÉRICA EN LA COYNTURA POLÍTICA DE VENEZUELA
}

\author{
NADESKA SILVA QUERALES
}

qué debe hacer, sino únicamente qué puede hacer y, en ciertas circunstancias, qué quiere. Es verdad que, en el campo de nuestras ciencias, las cosmovisiones personales se introducen de continuo también en la argumentación científica; la perturban siempre, y dejan traslucir su gravitación de maneras distintivas aún en el campo del establecimiento de simples conexiones causales entre los hechos, con el resultado, en cada caso, de aumentar o disminuir las chances de los ideales personales, a saber: la posibilidad de querer algo determinado".

${ }_{\mathrm{VII}}$ En adelante se comprende por legitimidad y dominación legal (racional con arreglo a fines y valores) el tipo-ideal elaborado por Weber $(2005,173-174)$ "La dominación legal descansa en la validez de las siguientes ideas, entrelazadas entre sí: 1. Que todo derecho, "pactado" u "otorgado", puede ser estatuido de modo racional -racional con arreglo a fines o racional con arreglo a valores (o ambas cosas)-, con la pretensión de ser respetado, por lo menos, por los miembros de la asociación; y también regularmente por aquellas personas que dentro del ámbito de poder de la asociación (en las territoriales: dentro de su dominio territorial) realicen acciones sociales o entren en relaciones sociales declaradas importantes por la asociación. 2. Que todo derecho según su esencia es un cosmos de reglas abstractas, por lo general estatuidas intencionalmente; que la judicatura implica la aplicación de esas reglas al caso concreto; y que la administración supone el cuidado racional de los intereses previstos por las ordenaciones de la asociación, dentro de los límites de las normas jurídicas y según principios señalables que tienen la aprobación o por lo menos carecen de la desaprobación de las ordenaciones de la asociación. 3. Que el soberano legal típico, la "persona puesta a la cabeza", en tanto que ordena y manda, obedece por su parte al orden impersonal por el que orienta sus disposiciones. Lo cual vale para el soberano legal que no es "funcionario", por ejemplo: el presidente electivo de un estado".

VIII En adelante se sigue a Max Weber $(2005,5$ y 18) en el uso del concepto acciones sociales: "Por "acción" debe entenderse una conducta humana (bien consista en un hacer externo o interno, ya en un omitir o permitir) siempre que el sujeto o los sujetos de la acción enlazan a ella un sentido subjetivo. La "acción social", por tanto, es una acción en donde el sentido mentado por su sujeto o sujetos está referido a la conducta de otros, orientándose por esta en su desarrollo.

... La acción social (incluyendo tolerancia u omisión) se orienta por las acciones de otros, las cuales pueden ser pasadas, presentes o esperadas como futuras (venganza por previos ataques, replica a ataques presentes, medidas de defensa frente ataques futuros). Los "otros" pueden ser individualizados y conocidos o una pluralidad de individuos indeterminados y completamente desconocidos ("el dinero", por ejemplo, significa un bien -de cambio- que el agente admite en el tráfico porque su acción está orientada por la expectativa de que otros muchos, ahora indeterminados y desconocidos, estarán dispuestos también, por su parte, en un cambio futuro".

IX Cabe destacar que entre las organizaciones opositoras participantes en los sucesos de 2002 y 2003 se encuentran los partidos Acción Democrática, el partido Social Cristiano COPEI, Primero Justicia y Proyecto Venezuela. Por el lado empresarial: la Federación Venezolana de Cámaras de Comercio y Producción (FEDECAMARAS) y el Consejo Nacional del Comercio y los Servicios (CONSECOMERCIO) en alianza con la Confederación de Trabajadores de Venezuela (CTV), organización sindical de inclinación patronal bajo la tradicional figura de la tripartita para las negociaciones de los contratos colectivos. La jerarquía de la Iglesia Católica reunida en la Conferencia Episcopal Venezolana también participó en estos hechos bajo el liderazgo visible del Cardenal Antonio Ignacio Velazco y Monseñor Baltazar Porras Cardozo, entre otras figuras de la jerarquía católica. La participación activa de los medios de comunicación social fue determinante, en particular el papel de los canales de televisión: Radio Caracas Televisión (RCTV), Venevisión, Globovisión y Televen.

${ }^{\mathrm{X}}$ Los gobiernos de Hugo Chávez Frías impulsaron una variedad de organizaciones para gestionar las Misiones Sociales y otras políticas públicas, por ejemplo los comités de tierra, los comités de salud, las mesas técnicas de agua, los núcleos de desarrollo endógeno, organizaciones de apoyo a la red Mercal en sectores rurales, cooperativas, bancos comunitarios, medios de comunicación alternativos hasta llegar en el año 2009 a la figura de los Consejos Comunales. Estas formas de organización social de base están originalmente inspiradas en la voluntad de construir la democracia participativa y protagónica prescrita en la Constitución de 1999. García Guadilla (2012) realiza un análisis crítico cobre la concepción y el funcionamiento de los Consejo Comunales para develar los rasgos clientelares presentes en algunas de estas experiencias. Por otra parte, en López Maya (2018) se puede apreciar un análisis crítico que expone 


\section{APUNTES SOBRE LA POSICIÓN DE LA ALIANZA BOLIVARIANA \\ PARA LOS PUEBLOS DE NUESTRA AMÉRICA EN LA COYNTURA POLÍTICA DE VENEZUELA}

\section{NADESKA SILVA QUERALES}

las contradicciones entorno a los Consejos Comunales, su relativa implantación y el alcance de un Estado comunal en Venezuela.

${ }^{\mathrm{XI}}$ En adelante se comprende por gobernabilidad democrática la definición aportada por Arbós y Giner (1996, 13): "la cualidad propia de una comunidad política según la cual sus instituciones de gobierno actúan eficazmente dentro de su espacio de un modo considerado legítimo por la ciudadanía, permitiendo así el libre ejercicio de la voluntad política del poder ejecutivo mediante la obediencia cívica del pueblo. Esta cualidad se expresa, esencialmente, en un proceso continuo de gobierno que obtiene un grado mínimo de obediencia ciudadana, una medida suficiente de aceptación popular, así como de las diversas instituciones (de la propia esfera política y de la sociedad civil) para que dicho proceso no tenga una existencia efímera".

XII Para una comprensión plural de los antecedentes, la concepción de política pública, los alcances e impacto de las Misiones Sociales en Venezuela se sugiere consultar Eljuri (2006), Silva Querales (2006), Patruyo (2008), D’Elia y Maingón (2009), Aponte (2012), Castro (2012) y Rodríguez (2018).

XIII En un trabajo previo analizamos la coyuntura y el proceso de diálogo político facilitado por la UNASUR en Venezuela, ver Silva Querales (2014).

XIV Silva Querales (2015).

XV Silva Querales (2014).

${ }^{\mathrm{XVI}}$ Telesur (07/12/2015): Maduro celebra triunfo democrático y reconoce resultados del 6D, en: https://www.telesurtv.net/news/Maduro-reconoce-resultados-y-afirma-que-ha-triunfado-la-democracia-20151206-0095.html (recuperado el 15/09/2019).

${ }_{\mathrm{XVII}}$ Telesur (05/01/2016): Ramos Allup asegura que sacará a Maduro en seis meses, en https://www.telesurtv.net/news/Ramos-Allup-asegura-que-sacara-a-Maduro-en-seis-meses-201601050039.html (recuperado el 15/09/2019).

XVIII Artículos 347, 348 y 349 de la Constitución de la República Bolivariana de Venezuela de 1999.

XIX Telesur (30/07/2017): ¿En qué consiste la Asamblea Constituyente convocada por el Gobierno venezolano?, en https://www.telesurtv.net/news/Venezuela-Asamblea-Nacional-Constituyente-201705010034.html (recuperado el 15/09/2019).

Xx Panorama (08/05/2017): MUD sobre Constituyente: Rechazamos participar en la fraudulenta e ilegítima propuesta de Maduro, en https://www.panorama.com.ve/politicayeconomia/MUD-sobreConstituyente-Rechazamos-participar-en-la-fraudulenta-e-ilegitima-propuesta-de-Maduro-20170508-

0076.html (recuperado el 15/09/2019).

${ }^{\mathrm{XXI}}$ En las elecciones presidenciales celebradas el 27 de octubre de 2019 en Argentina resultó triunfadora la opción del Frente de Todos, es decir, la fórmula política de Alberto Fernández y la ex presidenta Cristina Fernández de Kirchner (2007-2015). En estas elecciones fue derrotada la opción política liderada por el presidente en funciones Mauricio Macri (2015-2019) hasta el 10 de diciembre de 2019.

XXII El 9 de septiembre de 2019, Michelle Bachelett, Alta Comisionada de las Naciones Unidas para los derechos humanos, presentó un nuevo informe sobre la situación de los derechos humanos en Venezuela. En este documento se recogen denuncias de víctimas del conflicto y de la crisis económica, denuncias de organizaciones sociales, entrevistas a funcionarios del gobierno nacional y resultados de las visitas efectuadas por esta oficina de la ONU a Venezuela.

XXIII Ver informe de la OEA presentado el 31 de diciembre de 2017 sobre la situación de los derechos humanos en Venezuela. Por otra parte, la posición parcializada y pública del Secretario General de la OEA, Luis Almagro, a favor de los intereses de los partidos políticos y actores sociales opositores al gobierno de Maduro, así como el incumplimiento de las normas que rigen el funcionamiento de la OEA acarreó el retiro de Venezuela. El 26 de abril de 2017 en un ejercicio de soberanía el gobierno del presidente Nicolás Maduro denuncia la Carta de la OEA y el 27 de abril de 2019 se concretó formalmente el retiro definitivo de Venezuela.

XXIV De Alba, Mariano (2018).

XXV El 8 de agosto de 2017 es creado el Grupo de Lima a partir de la Declaración de Lima con la finalidad de presionar la salida del presidente Maduro, ofrecer apoyo internacional a la Asamblea Nacional electa en 2015 y respaldar las acciones de los partidos Primero justicia, Voluntad Popular y Acción Democrática. Esta instancia actúa de manera articulada con el gobierno de Estados Unidos y en el ámbito de la OEA. Una de las acciones del Grupo de Lima fue la desarticulación de UNASUR y la permanencia de la suspensión temporal de Venezuela en el MERCOSUR. 


\title{
APUNTES SOBRE LA POSICIÓN DE LA ALIANZA BOLIVARIANA \\ PARA LOS PUEBLOS DE NUESTRA AMÉRICA EN LA COYNTURA POLÍTICA DE VENEZUELA
}

\author{
NADESKA SILVA QUERALES
}

${ }^{\mathrm{XXVI}}$ El intento de magnicidio contra el presidente Maduro fue denunciado en instancias internacionales. Ver Telesur (10/08/2018). Venezuela no callará acción criminal perpetrada al presidente Maduro, en https://www.telesurtv.net/news/venezuela-denunciara-inten (recuperado el 15/09/2019).

XXVII Dólar Today y Monitor Dólar son los principales marcadores paralelos en el país que establecen el valor de la divisa en el mercado nacional. Esto constituye una de las mayores distorsiones en el funcionamiento de la economía venezolana.

XXVIII En el documento "La Responsabilidad de Proteger" presentado por la CIISE (2001) ante la ONU se establecen dos principios básicos para la intervención: “A. La soberanía de un Estado conlleva responsabilidades e incumbe al propio Estado la responsabilidad principal de proteger a su población. B. Cuando la población esté sufriendo graves daños como resultado de una guerra civil, una insurrección, la represión ejercida por el Estado o el colapso de sus estructuras, y ese Estado no quiera o no pueda atajar o evitar dichos sufrimientos, la responsabilidad internacional de proteger tendrá prioridad sobre el principio de no intervención".

XXIX BCV Estadísticas Producto Interno Bruto, en http://www.bcv.org.ve/estadisticas/producto-internobruto (recuperado el 15/09/2019).

XXX BCV Estadísticas Variaciones del Índice Nacional de Precios al Consumidor, en http://www.bcv.org.ve/estadisticas/consumidor (recuperado el 15/09/2019).

XXXI BCV Estadísticas Variaciones del Índice Nacional de Precios al Consumidor, en http://www.bcv.org.ve/estadisticas/consumidor (recuperado el 15/09/2019).

XXXII Finanzas Digital (09/10/2019): AN inflación en el mes de septiembre se ubicó en 23,5\% (anual 50.100,3\%), en https:/www.finanzasdigital.com/2019/10/an-inflacion-de-septiembre-2019-se-ubico-en235-anual-50-1003/ (recuperado el 23/10/2019).

XXXIII BCV Estadísticas Reservas Internaciones, en http://www.bcv.org.ve/estadisticas/reservasinternacionales (recuperado el 23/10/2019).

XXXIV BCV Estadísticas Deuda Externa, en http://www.bcv.org.ve/estadisticas/deuda-externa (recuperado el 15/09/2019).

XXXV Según informe publicado por la Organización de Países Exportadores de Petróleo (OPEP) la producción de crudo de Venezuela bajó 5,7\% (43 mil barriles diarios) durante los meses julio y agosto de 2019 ubicándose en 719 mil barriles diarios. Ver Finanzas Digital (11/09/2019): Informe OPEP: Venezuela bajó producción a $43.000 \mathrm{~b} / \mathrm{d}$ entre julio $\mathrm{y}$ agosto, en https:/www.finanzasdigital.com/2019/09/informe-opep-venezuela-bajo-produccion-a-43-000-bd-entrejulio-y-agosto/ (recuperado el 22/09/2019).

XXXVI En esta dirección electrónica puede consultarse las ediciones de ENCOVI: https://encovi.ucab.edu.ve/

XXXVII El CENDA publica las mediciones en su página oficial http://cenda.org.ve/default.asp

xXXVIII Telesur (20/05/2018): Nicolás Maduro gana las elecciones presidenciales en Venezuela, en https://www.telesurtv.net/news/venezuela-resultados-elecciones-nicolas-maduro-gana-201805180039.html (recuperado el 22/09/2019).

XXXIX Prodavinci (23/01/2019): 23 de enero: la marcha de la juramentación de Guaidó, en https://prodavinci.com/23-de-enero-la-marcha-de-la-juramentacion-de-guaido/ (recuperado el 25/09/2019).

${ }^{\mathrm{XL}}$ Las bases fundacionales del ALBA-TCP se encuentran en la Declaración conjunta Venezuela-Cuba de fecha 14 de diciembre de 2004. En este documento ambos mandatarios analizan las relaciones internacionales y el orden económico capitalista para entonces definir estrategias y acciones en América Latina y el Caribe. Este documento se considera el acta fundacional del mecanismo que posteriormente se convertiría en una alianza política con la incorporación de Bolivia, Nicaragua y Ecuador. El Proyecto Grannacional suscrito en Venezuela en 2007 constituye el plan de compromisos, acuerdos y proyectos.

${ }^{\text {XLI }}$ Véase Silva Querales y Delgado (2009), Silva Querales (2011), Briceño Ruiz (2014), SELA (2015) y Benzi (2016).

${ }^{\text {XLII }}$ El ministro de Comercio Exterior ecuatoriano, Pablo Campana, declaró en 2018 "Tenemos una agenda intensa con el sector privado y el sector público norteamericano (...) Se va a tratar, incluso lo que podría ser un cronograma o agenda para lo que sería un fortalecimiento de las relaciones comerciales a través de un acuerdo comercial justo y equitativo" (Sputnik, 09/11/2018).

XLIII ALBA-TCP (2018a). 


\section{APUNTES SOBRE LA POSICIÓN DE LA ALIANZA BOLIVARIANA \\ PARA LOS PUEBLOS DE NUESTRA AMÉRICA EN LA COYNTURA \\ POLÍTICA DE VENEZUELA}

NADESKA SILVA QUERALES

XLIV ALBA-TCP (2018a).

XLV ALBA-TCP (2018b).

XLVI ALBA-TCP (2018c).

XLVII ALBA-TCP (2019a).

XLVIII ALBA-TCP (2019b)

XLIX ALBA-TCP (2019c).

${ }^{\mathrm{L}}$ ALBA-TCP (2019d).

\section{Referencias bibliográficas y documentales}

ALBA (2004): Declaración Conjunta Venezuela - Cuba, I Cumbre del ALBA, La Habana 14 de diciembre de 2004.

ALBA (2005): Declaración Final Primera Reunión Cuba-Venezuela para la aplicación del ALBA, II Cumbre del ALBA, La Habana 27 y 28 de abril de 2005.

ALBA-TCP (2008): Conceptualización de Proyecto y Empresa Grannacional, VI Cumbre del ALBA, en https://www.alainet.org/es/active/21866 (recuperado el 12/05/2019)

ALBA-TCP (2011): Informe Anual 2011, publicación de la Secretaría Ejecutiva de la AlBA-TCP, Caracas.

ALBA-TCP (2018a): Declaración XV Cumbre del ALBA-TCP, en http://mppre.gob.ve/wp-content/uploads/sites/12/2018/03/Declaracion-del-ALBA-TCPESPA\%C3\%91OL-1.pdf http://mppre.gob.ve/2018/12/15/declaracion-cumbre-alba-tcphabana/ (recuperado el 14/03/2018).

ALBA-TCP (2018b): Declaración XVI Cumbre del ALBA-TCP, en http://mppre.gob.ve/2018/12/15/declaracion-cumbre-alba-tcp-habana/ (recuperado el 20/12/2018).

ALBA-TCP (2018c): ALBA-TCP condena atentado contra el Presidente de la República Bolivariana de Venezuela, en http://mppre.gob.ve/comunicado/alba-tcpcondena-atentado-contra-maduro/ (recuperado el 20/12/2018).

ALBA-TCP (2019a): Comunicado, 24 de enero de 2019, en https://www.prensa-latina.cu/index.php?o=rn\&id=247271\&SEO=alba-tcp-reiteraapoyo-a-mandato-presidencial-de-nicolas-maduro (recuperado el 15/10/2019).

ALBA-TCP (2019b): Comunicado del ALBA-TCP rechaza el intento de golpe de Estado en Venezuela, en http://mppre.gob.ve/wp-content/uploads/2019/04/AlbaTCP-rechaza-intento-de-golpe-de-Estado-en-Venezuela.pdf (recuperado el 15/10/2019).

ALBA-TCP (2019c): Declaración del XVIII Consejo Político del ALBA-TCP, en http://www.correodelorinoco.gob.ve/declaracion-del-xviii-consejo-politico-del-albatcp-celebrado-en-la-habana/ (recuperado el 15/10/2019).

ALBA-TCP (2019d): Consejo Político del Alba-TCP declara apoyo a Cuba y Venezuela ante las agresiones estadounidenses, en http://www.granma.cu/mundo/2019-09-23/consejo-politico-del-alba-tcp-declara-apoyoa-cuba-y-venezuela-ante-las-agresiones-estadounidenses (recuperado el 07/10/2019).

APONTE, Carlos (2012): La situación social de Venezuela: balance y desafíos. ILDIS, Caracas, en http://library.fes.de/pdf-files/bueros/caracas/09463.pdf (recuperado el 15/09/2019). 


\section{APUNTES SOBRE LA POSICIÓN DE LA ALIANZA BOLIVARIANA \\ PARA LOS PUEBLOS DE NUESTRA AMÉRICA EN LA COYNTURA \\ POLÍTICA DE VENEZUELA}

NADESKA SILVA QUERALES

Banco Central de Venezuela (2019): Estadísticas Producto Interno Bruto, en http://www.bcv.org.ve/estadisticas/producto-interno-bruto (recuperado el 15/09/2019).

Banco Central de Venezuela (2019): Estadísticas Variaciones del Índice

Nacional de Precios al Consumidor, en

http://www.bcv.org.ve/estadisticas/consumidor (recuperado el 15/09/2019).

Banco Central de Venezuela (2019): Estadísticas Variaciones del Índice

Nacional de Precios al Consumidor, en http://www.bcv.org.ve/estadisticas/consumidor (recuperado el 15/09/2019).

Banco Central de Venezuela (2019): Estadísticas Reservas Internaciones, en http://www.bcv.org.ve/estadisticas/reservas-internacionales (recuperado el 23/10/2019).

Banco Central de Venezuela (2019): Estadísticas Deuda Externa, en http://www.bcv.org.ve/estadisticas/deuda-externa (recuperado el 15/09/2019).

Benzi Danielle (2016): "El exitoso ocaso del ALBA", en Nueva Sociedad No 261, enero-febrero de 2016.

Briceño Ruíz, José (2014): El ALBA: una discusión de su modelo, sus resultados y sus perspectivas, Anuario de Integración 10, Coordinadora Regional de Investigaciones Económicas y Sociales, en http://www.cries.org/wpcontent/uploads/2014/11/6-Briceno.pdf (recuperado el 12/08/2019).

CASTRO, Jhonny (2012): "Las misiones sociales como políticas públicas en Venezuela: ¿un nuevo paradigma burocrático de ejercicio de gobierno?" en Mundo Nuevo, año IV, núm. 10, septiembre-diciembre, en http://www.iaeal.usb.ve/Mundo\%20Nuevo/MN\%2010/MN10_067-

097 JhonnyCastro.pdf (recuperado el 15/09/2019).

Comisión Internacional sobre Intervención y Soberanía de los Estados (2001): La

Responsabilidad

de

Proteger,

en http://www.ceipaz.org/images/contenido/La\%20responsabilidad\%20de\%20protege r_ESP.pdf (recuperado el 10/08/2019).

De Alba, Mariano (2019): La fase de investigación en la Corte Penal Internacional, en https://prodavinci.com/la-fase-de-investigacion-en-la-corte-penalinternacional/ (recuperado el 30/09/2019).

D'ELIA, Yolanda y Maingon, Thais (2009): La política social en el modelo Estado/gobierno venezolano, ILDIS, Caracas, en http://www.ildis.org.ve/website/p_index.php?ids=7\&tipo=P\&vermas=145 (recuperado el 15/09/2019).

ElJuri, Elías (2006): "Impacto social de las misiones barrio Adentro y Mercal", en Giordani, Jorge et al Inclusión social y distribución del ingreso, BCV, Caracas.

García-Guadilla, María Pilar (2012): "Democracia, inclusión y metodologías participativas: La experiencia de los consejos comunales en Venezuela", en Villasante Tomás et al: Construyendo democracias y metodologías participativas desde el Sur, LOM Ediciones, Santiago de Chile.

Instituto Nacional de Estadística (2018): Estadísticas de Pobreza 1999-2018, en http://www.ine.gov.ve/index.php?option $=$ com_content $\& v i e w=$ category\&id $=104 \&$ Itemi $\mathrm{d}=\#$ (recuperado el 12/07/2019). 


\section{APUNTES SOBRE LA POSICIÓN DE LA ALIANZA BOLIVARIANA \\ PARA LOS PUEBLOS DE NUESTRA AMÉRICA EN LA COYNTURA \\ POLÍTICA DE VENEZUELA}

NADESKA SILVA QUERALES

López Maya, Margarita (2018): "Socialismo y comunas en Venezuela", en Nueva Sociedad 274, Marzo - Abril, en https://nuso.org/articulo/socialismo-y-comunas-envenezuela/ (recuperado el 15/09/2019).

Organización de Estados Americanos (2017): Institucionalidad democrática, Estado de derecho y derechos humanos en Venezuela, Comisión Interamericana de Derechos Humanos, OEA/Ser.L/V/II. Doc. 209.

Organización de las Naciones Unidas (2019): Informe de la Alta Comisionada de las Naciones Unidas para los Derechos Humanos sobre la situación de los derechos humanos en la República Bolivariana de Venezuela, en https://www.ohchr.org/EN/HRBodies/HRC/RegularSessions/Session41/Documents/A HRC_41_18_SP.docx (recuperado el 07/10/2019).

Patruyo, Thanaly (2008). El estado actual de las misiones sociales: balance sobre su proceso de implementación e institucionalización, ILDIS, Caracas.

Panorama (08/05/2017). MUD sobre Constituyente: Rechazamos participar en la fraudulenta e ilegítima propuesta de Maduro, en https://www.panorama.com.ve/politicayeconomia/MUD-sobre-ConstituyenteRechazamos-participar-en-la-fraudulenta-e-ilegitima-propuesta-de-Maduro-201705080076.html (recuperado el 15/09/2019).

Prodavinci (23/01/2019): 23 de enero: la marcha de la juramentación de Guaidó, en https://prodavinci.com/23-de-enero-la-marcha-de-la-juramentacion-deguaido/ (recuperado el 25/09/2019).

Rodríguez, Francisco (2018): Las Misiones Sociales Bolivarianas: Una política pública con enfoque de derechos fundamentales en el Estado de Justicia Social., CLACSO e Instituto de Altos Estudios Diplomáticos Pedro Gual, Caracas.

SELA (2015): La Alianza Bolivariana para los Pueblos de Nuestra AméricaTratado de Comercio de los Pueblos, XLI Reunión Ordinaria del Consejo Latinoamericano Caracas, Venezuela 25 al 27 de noviembre de 2015 SP/CL/XLI.O/Di $\mathrm{N}^{\mathrm{o}} 11-15$

Silva Querales, Nadeska (2006): “Organizaciones y redes sociales en las políticas de inclusión social" en Giordani, Jorge et al Inclusión social y distribución del ingreso, $\mathrm{BCV}$, Caracas.

Silva Querales Nadeska y Delgado Gerardo (2009): "La Alianza Bolivariana para los Pueblos de Nuestra América: Año 2009", en Revista Política Exterior y Soberanía, Instituto de Altos Estudios Diplomáticos "Pedro Gual", Año 4, No 2, juliodiciembre, Venezuela.

Silva Querales, Nadeska (2011): “Crisis sistémica mundial y la experiencia de integración impulsada por la Alianza Bolivariana para los Pueblos de Nuestra América", en Revista Política Exterior y Soberanía, Instituto de Altos Estudios Diplomáticos "Pedro Gual", Año 6, No 1, enero-junio, Venezuela.

Silva Querales, Nadeska (2013): "Democracia, representación política y elitismo. Una aproximación sociológica a las ideas de Peter Bachrach". Revista Politeia $\mathrm{N}^{\circ} 50$ vol. 36. Instituto de Estudios Políticos, UCV.

Silva Querales, Nadeska (2014): "Participación de Unasur en el proceso de diálogo político en Venezuela" en Revista Politeia , $\mathrm{N}^{\circ}$ 53, vol . 37. Instituto de Estudios Políticos, UCV. 


\section{APUNTES SOBRE LA POSICIÓN DE LA ALIANZA BOLIVARIANA \\ PARA LOS PUEBLOS DE NUESTRA AMÉRICA EN LA COYNTURA \\ POLÍTICA DE VENEZUELA}

NADESKA SILVA QUERALES

Silva Querales, Nadeska (2015): La situación política de Venezuela en la agenda institucional de la ALBA y la UNASUR Cadernos do Tempo Presente, n. 21, set./out. 2015, p. 2-30| http://www.seer.ufs.br/index.php/tempo

Telesur (07/12/2015): Maduro celebra triunfo democrático y reconoce resultados del 6D, en: https://www.telesurtv.net/news/Maduro-reconoce-resultados-yafirma-que-ha-triunfado-la-democracia--20151206-0095.html (recuperado el 15/09/2019).

Telesur (05/01/2016): Ramos Allup asegura que sacará a Maduro en seis meses, en https://www.telesurtv.net/news/Ramos-Allup-asegura-que-sacara-a-Maduroen-seis-meses-20160105-0039.html (recuperado el 15/09/2019).

Telesur (30/07/2017): ¿En qué consiste la Asamblea Constituyente convocada por el Gobierno venezolano?, en https://www.telesurtv.net/news/VenezuelaAsamblea-Nacional-Constituyente-20170501-0034.html (recuperado el 15/09/2019).

Telesur (20/05/2018): Nicolás Maduro gana las elecciones presidenciales en Venezuela, en https://www.telesurtv.net/news/venezuela-resultados-elecciones-nicolasmaduro-gana-20180518-0039.html (recuperado el 22/09/2019).

Weber, Max (2005): Economía y sociedad, Fondo de Cultura Económica, España.

Weber, Max (2006a): "Sobre algunas categorías de la sociología comprensiva", en Weber, Max: Ensayos sobre metodología sociológica. Amorrortu Editores, Argentina.

Weber, Max (2006b): "La objetividad cognoscitiva de la ciencia social y de la política social", en Weber Max: Ensayos sobre metodología sociológica, Amorrortu Editores, Argentina. 